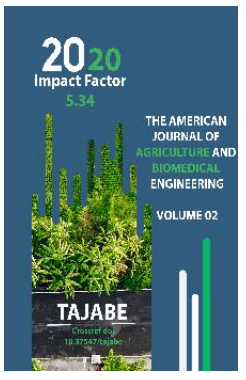

\title{
New Classification Of Ontogenesis About
}

\author{
Xoliqnazarov Begali Odinaevich \\ Teacher, Termez State University, Uzbekistan
}

Copyright: Original

content from this work may be used under the terms of the creative commons attributes 4.0 licence.

\section{ABSTRACT}

The article analyzes the history and essence of ontogeny, its composition and newly classified, offers and conclusions.

The concepts of ontogenesis, developmental cycle are used in almost all academic and some scientific literature by the authors in the same or similar meanings without knowing the meaning $[1,2,3,4,13,14]$.

\section{KEYWORDS}

Ontogeny, development cycle, ontogeny structure, direction, types, stages, cycles

\section{INTRODUCTION}

Ontogeny and development cycle history. The ontogenesis and developmental cycle of animals were first studied by the ancient Chinese. In particular, with the development of silkworm breeding, the Chinese were well aware that the development of the mulberry silkworm consisted of stages. Aristotle also said that after a worm-shaped larva reaches a certain size, it temporarily transforms back into an egg shape (i.e., a sponge) before reaching the end of its development.
Europeans rediscovered metamorphosis in the 17th century. Swammerdam (1737) took metamorphosis as a sign of death and resurrection, and used it to prove the theory of preformism that the buds of all the organs of the imagination in the dome are small. Although malaria plasmodia and the disease it causes were known to the Egyptians 3,000 years before Christ, its developmental cycle was determined in the 1950 s $[4,5,7,8]$. 
E. Haeckel (1866) first used the term ontogeny to prove biogenetic law and used it to describe embryonic development.

A.A. Zakhvatkin (1953) equates them with two: concepts of ontogeny and the developmental cycle as concepts with the same or similar meanings. In most cases, this is true, but sometimes there are exceptions to this rule. For example, in the developmental cycle of hydroids, moxibustion, ferns, etc., the correct gallium of sexual and asexual reproduction occurs. In this case, the ontogeny and developmental cycle cannot be equated. In this case, two ontogenesis in one complete developmental cycle, two developmental cycles in one complete ontogeny can be encountered. In many simple animals, the transition from asexual reproduction to sexual reproduction occurs as a result of the adverse effects of abiotic factors. Under such conditions, gene recombination prepares material to adapt to selection. Under constant favorable conditions, simple animals reproduce in large numbers asexually by prolonged cytotomy. As a result, under such adaptive conditions, the number of individuals of the species increases without changing the genotype. O.M. According to Ivanova-Kazas (1995), "The metazoan developmental cycle normally begins with the zygote and ends with death, but during this time the adult individual forms the germ cells that initiate the new cycle. Such a developmental cycle is synonymous with ontogeny in terms of meaning. " G. Egersten (1972) also referred to this situation when thinking of the lower Metazoa pelago-benthos cycle. $[4,9,16,17]$. In multicellular organisms, the initial stage of ontogeny is the onset of germ cell maturation, not the zygote (B.L. Astaurov, 1964). There are also different opinions about the final stage of ontogeny. Emriologists and morphologists consider this stage to be the period of sexual maturation. Because during this period the formation of tissues and organs is completed. When physiologists and naturalists say that the final stage of ontogeny is death, the Dutch emryologist P. Schmidt calls the life cycle from zygote to zygote, from adult organism to adult organism, ontogeny. If the term ontogeny means the life cycle of organisms, then it should be noted that ontogeny consists of different periods $[10,12,15]$. Thus, although the developmental cycle of animals and plants has been studied since ancient times, historical data have not yet been fully formed.

The essence of ontogeny. Generally, ontogeny is the sum of the periods of an organism from zygote to natural death. However, ontogeny may not end in death. For example, when a simple amoeba divides and multiplies, when the cercaria is formed from the radium, the ontogeny of the mother amoeba or radium ends, but death does not occur. Z.S. Kaufman (1990) asexual reproduction does not lead to the formation of a new generation, the set of individuals formed from one egg constitutes one generation. The jellyfish form is genetically identical to the polyp form, the difference being age-related. That is why they should not be considered as two different generations. " If in the process of reproduction the organism is completely divided and disappears, and its body is used for the formation of a new organism, then in this case all individuals formed from one organism form a single ontogeny $[4,5,6,15,18]$.

Based on the above analysis, we propose to define ontogeny as follows: ontogeny is the sum of the processes of infinite formation of new individuals from the maturation of the zygote-producing gametes or the beginning of another type of reproduction to the natural death of the individual.

The structure of ontogenesis and its new classification.

1. Directions of ontogeny. Depending on whether the life of an organism ends 
during the life of that organism, there are two directions of ontogeny: mortal and immortal (table). Such an ontogeny is called a dying ontogeny if the organism, which is formed by some type of reproduction, undergoes embryonic and postembryonic stages, i.e., reproductive involution, and natural death in old age. For example, vertebrates reproduce sexually and age and die at the end of their lives. [4,9,10,17]. The set of cells formed as a result of a single cell division, as well as the sum of individuals formed by simple division such as simple amoebae, green euglena, and so on, are individuals of the same generation, which must also be considered as a single ontogenetic product. This is because after each division and reproduction, a new individual is formed before the end of ontogeny (without death). These individuals are genetically similar, but may have some differences morphologically and physiologically. In the process of division and reproduction, the mother individual does not die, but is divided into two or more "daughter" individuals. For example, when any cell or simple amoeba divides and multiplies, the mother individual divides to form two new female individuals, and the mother individual divides into female individuals, that is, the female individual forms an organism. In short, in such cases, ontogeny does not end in death, and therefore this aspect of ontogeny is called immortal ontogeny.

2. Types of ontogeny. There are two types of ontogeny: straight and metamorphosed, depending on the degree of development of the new generation, which arises when the organism reproduces, similar to the parental forms. Proper development is similar to the shape of a sexually mature child in terms of the structure of the newborn or egg, the difference is the small size of the body, the inability to fully perform the function of organs, the incomplete formation of certain organs. Some animals also give birth to live larvae or live larvae under various adverse conditions. There are also two types of proper development: 1 . Animals that enter the developmental cycle without larvae lay eggs that are rich in yolk. Therefore, a certain part of ontogeny takes place inside the egg laid in the external environment. Metabolism and other physiological processes in the embryo are carried out by the embryonic shell (yolk sac, amnion, chorion, allantois). Larvae-free development occurs in flatworms, gnats, caterpillars, leeches, spiders, some fish, reptiles, birds, and other animals [14]. Completely altered or metamorphosed development emerged during evolution as a device for adapting, reproducing, and surviving an embryo under certain environmental conditions. Under the influence of metamorphosis endocrine system, the larva that hatches from the egg resembles the parental form after several changes. In this way, insects, amphibians develop.

3. Stages of ontogeny. The stage of ontogeny is when the place of life (mother's body or external environment) in the process of individual development of an organism differs sharply from the place of subsequent development. There are two distinct stages of ontogeny: embryonic and postembryonic. The embryonic stage includes the stage from the beginning of germ cell maturation to the formation of the zygote until the embryo is born. The postembryonic stage includes the stage from embryonic birth to natural death.

4. Periods of ontogeny. Processes that differ in structure even if their development takes place in a single stage of ontogeny are called periods of ontogeny. For example, although the zygote, blastula, gastrula, and neuronal cycles pass through the embryonic stage, each of them is a 
separate ontogenetic cycle because they differ in structure.

In terms of ontogeny, reproduction can be divided into the following four stages:

1. Reproductive maturation includes all embryonic and postembryonic stages from the beginning of the maturation of the germ cells that make up the stepparent organism to the formation of the zygote and the new individual. takes This stage is relatively long in live-born highly structured animals (mammals) and shorter in egg-laying animals (insects).

2. The reproductive stage includes the stage from the maturation of the germ cells to the laying of the egg or the birth of the embryo, that is, the stage from the beginning of each reproductive process to the laying of the embryo.

3. In the reproductive mesopause stepontogenesis, we propose to call the intermediate stage, which passes from one reproduction of the individual to the second reproduction, the reproductive mesopausal stage of ontogeny. In this case, the number of reproductive mesopauses occurs as many times as an individual's life. For example, if butterflies multiply 6 times in their lifetime, reproductive mesopause occurs 6 times. The reproductive mesopause phase also consists of 3 stages:

After reproduction in the first period, the body prepares itself for recovery (such as menstruation or the interphase phase of cell division),
In the second period, synthesis processes take place and the organism regenerates itself, in the third stage it is prepared for the next reproduction. Reproductive mesopause lasts only a short time, given that in animals that reproduce by laying eggs, only energy is expended to mature and lay an egg. Therefore, the time from laying one egg to another is relatively short. In animals that give birth to a live child or a live egg, the reproductive mesopause lasts longer because the embryo or live egg is stored in the mother's body for a long time. During this period, reproduction also stops. This period should be called the period of reproductive pause. Because the embryo and mother are directly connected (via the placenta), they have more time to recover and prepare for the next reproduction.

4. Reproductive involution involves the stage from the last laying, the birth of the embryo to the natural death. During this stage, the organism does not multiply, but ages and dies, thus ending ontogeny. Ontogeny includes all stages of reproduction and survival, and the developmental cycle includes the reproductive stage and the reproductive mesopause stages. Ontogenesis is a type, individual development is a concept related to the individual. The duration of individual development within a species may vary depending on external environmental factors. The total sum of these is the ontogenesis of the species.

1-table

Ontogenetic structure and its classification

\begin{tabular}{|c|c|c|c|}
\hline № & Ontogeny & Types & Brief description \\
\hline 1 & Directions & Immortal & $\begin{array}{l}\text { Due to asexual reproduction, the organism } \\
\text { divides and its body is used to form a new }\end{array}$ \\
\hline
\end{tabular}




\begin{tabular}{|c|c|c|c|}
\hline & & & organism. In this case, death does not occur. \\
\hline & & Dying & $\begin{array}{l}\text { Organisms whose end of individual development } \\
\text { ends in death, mainly sexual reproduction }\end{array}$ \\
\hline \multirow[t]{2}{*}{2} & \multirow[b]{2}{*}{ Types } & $\begin{array}{c}\text { Proper } \\
\text { development }\end{array}$ & $\begin{array}{l}\text { From a developing embryo in an egg or in the } \\
\text { mother's body, a child resembles a parental form. }\end{array}$ \\
\hline & & $\begin{array}{l}\text { Metamorphosed } \\
\text { development }\end{array}$ & $\begin{array}{c}\text { A baby hatched from an egg does not look like a } \\
\text { parent's uniform }\end{array}$ \\
\hline \multirow[t]{2}{*}{ 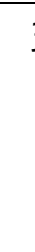 } & \multirow[t]{2}{*}{ Stages } & Embryonic & $\begin{array}{l}\text { The stage from the maturation of germ cells to } \\
\text { the formation of the zygote before the embryo is } \\
\text { born }\end{array}$ \\
\hline & & Postembryonic & The stage from embryonic birth to natural death \\
\hline \multirow[t]{4}{*}{4} & \multirow{4}{*}{ Periods } & Egg (zygote) & $\begin{array}{l}\text { From the formation of germ cells to the } \\
\text { formation of the zygote (egg) until the } \\
\text { emergence of lichen from the egg }\end{array}$ \\
\hline & & Larva & $\begin{array}{l}\text { Independently feeds, grows, forms the } \\
\text { characteristics of the next period }\end{array}$ \\
\hline & & G'umbak & $\begin{array}{l}\text { Inside the shell, the lichen organism is rebuilt and } \\
\text { definitive organs are formed }\end{array}$ \\
\hline & & imago & The period of sexual maturity \\
\hline
\end{tabular}

\section{CONCLUSION}

1. The Society of Biologists of Uzbekistan should be established, one of which should analyze the current state of laws, rules, theories and terms in all areas of biological science, enrich it with relevant news and create a constantly updated electronic platform. This is a very largescale work, which should involve scientists from all research institutes and higher education institutions in the country, as well as members of the general public.

2. Although there are many species of living organisms in nature, it is necessary to systematically develop and monitor scientific work in this area, given that a comprehensive study of the ontogenesis and development cycle of very few of them does not allow the creation of the theory and classification of ontogeny and development cycle.

3. The principles and rules on which the theory and classification of ontogeny and development cycles are based should be developed.

4. The origin and evolution of the ontogeny and development cycle, their similarities as well as differences should be determined. 
5. The practical significance of the ontogeny and development cycle (in agriculture, medicine) should be revealed.

\section{REFERENCE}

1. L.V. Belousov Fundamentals of General Embryology. M .: Science; Publishing house of Moscow State University. 2005.368p.

2. Gilbert S. Developmental Biology. Moscow: Mir, 2010.

3. Golichenkov V.A., Ivanov E.A., Nikeryasova E.N. Embryology. M .: Academy, 2004.

4. Ivanova-Kazas OM Evolutionary embryology of animals. St. Petersburg: Science. 1995.566 p.

5. Kaufman Z.S. Essay on the evolution of coelenterates. Petrozavodsk, 1990.155 p.

6. Korochkin L.I. Biology of individual development. $M$.: Publishing house MRU 2002.263p.

7. Kolot N.V., Volkova N.E., Vorobieva L.I. Ontogenesis mechanisms. Kharkov.: Publishing house of the Kharkov National University. 2015.219 p.

8. Martynov A.V. Ontogenetic systematics and a new evolutionary model of Vilateria. M. Fellowship of scientific publications KMK. 2011.286 p.

9. Ozernyuk N.D., Isaeva V.V. Evolution of ontogeny. Moscow: KMK Scientific Publishing Association. 2016.407 p

10. Ruppert E.E., Fox R.S., Barnes R.D. Zoology of invertebrates. $M$.: Academy, vol. 1, 2008.

11. Raff 3., Kofman T. Embryos, genes and evolution. Moscow: Mir, 1986.404 p.

12. Severtsov A.N. Morological patterns of evolution. M., L. 1939. $609 \mathrm{p}$

13. Xoliqnazarov B. Biology of individual development. $\mathrm{T}$ : Uzbekistan Literature Foundation Publishing. 2006. 368 p.

14. Kholiknazarov B. Biogenetic law, ontogeny, development cycle: history, current status, problems and solutions. Khiva. Khorezm Mamun Academy. 2019. №1, 13-20 p.
15. Gilbert S.F., Barresi M.J.F. Developmental Biology. 11th ed. - Sunderland, Massachusetts, USA, 2016. $940 \mathrm{p}$

16. JagerstenG. Evolution of the metazoan lite cycle. London, New York, 1972. 282p.

17. Gould S. J. Ontogeny and Phylogeny. Cambridge: Cambridge University Press. 1977. $501 \mathrm{p}$.

18. Minelli A. EvoDevo and its significance for animal evolution and phylogeny // Evol. Devel. Biol. Ivertebr. Ed. Wanninger A. V. 1. Wien.: Springer. 2015. P 1-2 